\title{
Cell proliferation markers in oral squamous cell carcinoma
}

Maiara de Moraes ${ }^{1 *}$, Conceição Aparecida Dornelas Monteiro Maia ${ }^{1}$, Roseana de Almeida Freitas² and Hébel Cavalcanti Galvão²

${ }^{1} D D S$, Oral Pathology, Federal University of Rio Grande do Norte, Natal, RN, Brazil

${ }^{2} D D S$, Oral Pathology, Federal University of Rio Grande do Norte, Natal, RN, Brazil

\begin{abstract}
Summary
The discovery and characterization of genes and molecules involved in oral carcinogenesis have contributed to the diagnosis, assessment of prognosis and survival of patients with oral cancer. The knowledge of etiological and biological mechanisms involved in cancer allows important advances in diagnosis and therapeutics. Numerous parameters are used to measure the aggressiveness of a tumor, among which cell proliferation stands out, an important phenomenon related to the behavior of lesion and that is linked to dysregulation of the cell cycle machinery in various cancers. Scientific researches have been conducted to investigate these events. This review discusses the use of cell proliferation markers in oral cancer, particularly oral squamous cell carcinoma, emphasizing those related to cell proliferation rate, such as PCNA, Ki-67, AgNORs, cyclins, MCM and geminin. Criteria used for diagnostic and prognostic such as clinical stage, size and location of lesions, margin of lesions, associated with the use of these biomarkers offer valuable opportunities to evaluate the behavior of the disease and, moreover, are of great prognostic value.
\end{abstract}

Keywords: Cell proliferation; Biomarker; Cell cicle; Oral squamous cell carcinoma.

\section{Introduction}

The most common malignant epithelial neoplasm in the oral cavity is the oral squamous cell carcinoma (OSCC), representing over $90 \%$ of malignancies of the oral cavity. The information obtained in the clinical and histopathological examinations is not always satisfactory for the diagnosis and prognosis of these lesions. Therefore, more specific methods are used to allow the measurement of the cellular alterations present in these lesions by means of cellular and tissue markers.

Biological biomarkers are cellular, structural and biochemical components that can define cellular and molecular alterations in both normal cells and those associated with malignant transformation. They can be divided into intermediate markers, which measure cellular and molecular alterations before the onset of the malignant neoplasm, and diagnostic markers, which are useful in confirming the malignant lesion established. The biomarkers with diagnostic purposes are used in the clinical management of individuals with cancer, helping in the process of staging, type of therapy, evaluation of treatment response, detection of recurrence and prognosis [1].

Several markers have been used in order to provide additional information about these tumors, including the inactivation of tumor suppressor genes, angiogenesis, apoptosis and cell proliferation markers, which have long been used in the study of cancer and is the focused of this study. Cell proliferation is a biological process vitally important to all living organisms due to its role in the growth and maintenance of tissue homeostasis [2]. The control of this important process is completely dysregulated in cancer $[1,3]$ and the assessment of cell proliferation activity in tumors has become a common tool used by histopathologists in order to provide useful information for diagnosis, clinical behavior, and therapy. This review aims to discuss the main biological markers used to assess cell proliferation activity in oral squamous cell carcinoma addressing the most current research.

\section{Review of Literature}

\section{Cell cicle and cell proliferation markers}

Many of the molecular alterations that cause abnormal biological behavior of cancer cells are based on aberrations of cell cycle regulation.
For example, tolerance to DNA damage, apoptosis resistance, and progression of cells with activated oncogenesis and/or inactivated tumor suppressor genes through multiple checkpoints resulting in increased genomic instability-all affect and/or are affected by cell cycle regulatory proteins [4].

The cell cycle consists of a series of phases during which there are changes that lead to cell division. Cell regulatory genes modulate the cell cycle in a highly sophisticated fashion, via a number of proteins [5]. The transition from one phase to the next is checked at a 'checkpoint' before the cycle can progress. The cell cycle consists of a stationary G0 phase which, upon receipt of appropriate cell signals, is followed by entry into G1, S, and G2, before mitosis (M) (Figure 1) [5].

Checkpoint genes not only control transition between phases of the cell cycle but also coordinate cell cycle progression with cell signals. When DNA is damaged, there may be arrest of the cell cycle which can facilitate DNA repair. G1 arrest prevents replication of a damaged DNA template and G2 arrest allows the segregation of damaged chromosomes. Checkpoint genes can modulate regulation of the integrity of the genome if the DNA damage is such as not to immediately cause cell death. The main factors regulating cell cycle progression include cyclins and their kinases (cyclin-dependent kinases $(\mathrm{CDKs})$ ) and inhibitory enzymes, the retinoblastoma $(\mathrm{Rb})$ protein, $\mathrm{p} 21$, p27 and p53 [4,5].

The decision to activate the cascade of events leading to DNA synthesis and ultimately cell division occurs at the restriction point

\footnotetext{
*Corresponding author: Maiara de Moraes Universidade Federal do Rio Grande do Norte - Departamento de Odontologia Av. Senador Salgado Filho, 1787 - Lagoa Nova - Natal - RN CEP 59056-000, Brazil, Tel / Fax: (84) 3215-4138; E-mail: maiaramoraes@gmail.com

Received December 01, 2011; Accepted December 18, 2011; Published January 07, 2012

Citation: de Moraes M, Monteiro Maia CAD, de Almeida Freitas R, Galvão HC (2012) Cell proliferation markers in oral squamous cell carcinoma. J Mol Biomark Diagn S2:006. doi:10.4172/2155-9929.S2-006

Copyright: @ 2012 Moraes Md, et al. This is an open-access article distributed under the terms of the Creative Commons Attribution License, which permits unrestricted use, distribution, and reproduction in any medium, provided the original author and source are credited
} 
(R). The sum of signals accumulated in the first two-thirds of the G1 phase may trigger cell cycle progression, cause the cell to revert to G0 phase (or quiescence), or lead to cellular differentiation. After passing the restriction point late in G1, a cell will disregard exogenous signals and will enter DNA synthesis. Thus, the molecular mechanisms that control the progression through the restriction point are of central importance in governing entry into the cell cycle. After DNA synthesis, major intracellular insults, such as genomic damage or metabolic disruption can halt cell cycle progression, and the cells will be arrest at other checkpoints in S, G2, or M phase (Figure 1) [4]. Oral cancer appears as a consequence of multiple molecular genetic events in many chromosomes and genes. The consequence of this chromosomal (genetic) damage is cell dysregulation with disruption in cell signaling, cell growth cycle, and/or mechanisms to repair cell damage or eliminate dysfunctional cells.

Numerous techniques have been developed to detect and quantify proliferating cells in various malignancies. The pioneer method was based on the counting of mitosis figures using a light microscope, but this way only cells present in the $\mathrm{M}$ phase could be quantified due to its specific feature in the hematoxylin-eosin staining [6]. Techniques to evaluate cells that were present in the $S$ phase of cell cycle were developed later. One of them was based on the use of the tritium labeled thymidine (tritiated thymidine) and the other involved the use of another pyrimidine analogue, the bromodeoxyuridine (BrdU). The results obtained with both techniques were similar. However, the technique of BrdU had the disadvantage of requiring prior administration of the pyrimidine analogue in patients. In addition, these techniques were difficult and costly, time consuming and often requiring sophisticated equipment, limiting its routine use by pathologists $[6,7]$.

Recently, other techniques have been used for the measurement of cell proliferation rate including flow cytometry, which analyzes the percentage of cells in specific phases of the cell cycle and other techniques with immunohistochemistry, genomics and proteomics techniques [7]. The proliferative activity of a tissue or a tumor is measured by determining the mean growth fraction and mean cycle time of cells. The growth fraction, i.e. the proportion of the cells committed to the cycle, may be easily assessed by Ki-67 or MIB- 1 antibodies, which identify an antigen expressed in G1, S and G2 phases of cycling cells. The M-phase can be evaluated by counting the mitotic figures. S-phase fraction (SPF)



Figure 1: can be assessed by incorporation techniques, such as the in vivo or in vitro incorporation with titrated thymidine (TH3) or BrdU or flow cytometry analysis of the DNA, or the immunohistochemical detection of proliferating cell nuclear antigen (PCNA), a nuclear protein involved in DNA synthesis. Cell cycle time can be evaluated by the potential doubling time, a procedure that requires in vivo intravenous BrdU infusion, or by the quantification of the argyrophilic proteins associated with the nucleolar organizer regions (AgNORs) $[1,8]$. Therefore, the cell proliferation markers can be grouped into three main categories: (a) growth fraction markers, such as Ki67, (b) cycle-specific markers (e.g., PCNA), and (c) cell cycle time markers (e.g., AgNOR), strictly related to the rapidity of cell proliferation [8]. Some of markers of cell proliferation in oral cancer are discussed below.

\section{Cell proliferation markers in oscc}

\section{Cell cycle time markers}

- AgNORs: The nucleolar organizer regions (NORs) are the regions of chromatin corresponding to the secondary constrictions of chromosomes responsible for transcription of ribosomal RNA (rRNA). They are intimately associated with the nucleolus, which plays an important role in cell proliferation controlling and protein synthesis [9].

The NORs are argyrophilic regions and can be viewed on the silver staining, and so are named argyrophilic proteins associated with NORs (AgNORs), i.e., a group of nucleolar proteins with high affinity for silver and that are easily identified as black dots located exclusively in whole nucleolar area [10]. The expression of AgNORs is strictly related to the doubling time and cell rapidity, and studies in different tumors revealed that malignant cells often present higher amounts when compared to non-malignant cells [11].

Moreover, when evaluated in the invasive front of oral carcinomas, the AgNOR were highly correlated with poor prognosis when compared with the evaluation to the fullest extent of the tumor $[8,12]$. According to Piffkò et al. [12], the rapidity of cell proliferation evaluated by AgNOR quantification is probably the kinetic parameter which correlates better with the outcome of OSCC. This finding suggests the use of an aggressive surgical approach for those patients with a high AgNOR quantity. Recently, Lopez-Blanc et al. [13] state that variations in AgNOR epithelial could serve as practical biomarker to assess changes in the risk of cancer in the oral mucosa.

\section{Growth fraction markers}

- Ki-67: The monoclonal antibody Ki-67 was first identified at the University of Kiel, Germany, and obtained through the 67th tissue culture plate [3]. The Ki-67 is a nuclear non-histone protein, with unknown chemical structure and molecular weight ranging from 345 to $395 \mathrm{kDa}$. It is encoded by a gene located on chromosome 10q25, containing phosphorylation sites for a variety of kinases $[3,14,15]$, playing roles in cell cycle regulation, synthesis of ribosomes and also being related to survival, malignancy and prognosis of various neoplasms, including OSCC. The expression of Ki-67 occurs during all phases of the cell cycle except in the G0 phase and in the early G1 phase, and it increases as cell proliferation progresses, especially in the $S$ phase, with peaks in G2 and M phases, being degraded rapidly after mitosis [15].

In the study of growth fraction in human tumors, the application of $\mathrm{Ki}-67$ is an easy and useful method because it can provide useful 
Citation: de Moraes M, Monteiro Maia CAD, de Almeida Freitas R, Galvão HC (2012) Cell proliferation markers in oral squamous cell carcinoma. J Mol Biomark Diagn S2:006. doi:10.4172/2155-9929.S2-006

information for the prognosis of the lesions. In OSCC, the increased rate of Ki-67 has been correlated with poor survival, high degree of malignancy and histological grading in the invasive front (Table 1) [1522].

\section{Cycle-specific markers}

- PCNA: PCNA is a ring shaped trimeric complex with essential roles in DNA synthesis associated with both DNA replication and repair. PCNA forms a sliding platform required for the processivity of DNA polymerases $\delta$ and $\varepsilon$ during DNA replication [23]. Due to its mobility inside nuclei, PCNA is dynamically presented in a soluble or chromatin-associated form. The heterogeneity and specific modifications of PCNA may reflect its multiple functions and the presence of many binding partners in the cell [24]. PCNA interacts with proteins involved in the cell cycle regulation and controls checkpoints, functioning as an essential component in the machinery of DNA replication $[23,25]$. Studies have shown that PCNA helps DNA polymerase- $\delta$ by removing nucleotides, forming a quaternary complex with the p 21 protein, cyclin D and CDK [24]. Therefore, the expression of this antigen is not only related to cell proliferation, but also with different functions such as in nucleic acid metabolism, DNA repair, chromatin assembly and RNA transcription $[23,25]$. The results of major studies on OSCC can be found in Table $1[17,19,22]$.

\section{Cyclins}

The cyclins together with cyclin-dependent kinases (CDKs) are proteins responsible for the orderly progression of cells through the cell cycle. Changes in the genes encoding these proteins as well as changes in the expression of these proteins are found in the process of carcinogenesis. Overexpression of this protein leads to uncontrolled cell proliferation and tumor development [26].

The cyclins can be subdivided into G1 cyclins, which regulate the passage of cells in the G1 phase to the S phase (cyclins C, D1-D3, E) and mitotic cyclins that facilitate the passage of the cells during mitosis (cyclins A and B) [27]. Cyclins are synthesized during specific phases of the cell cycle. Each type will appear in sequence and its function is to activate the CDKs that are in inactive form. The first cyclin to increase in the cell cycle is cyclin D. It arises in the mid G1 phase and is no longer detected at the S stage. During the G1 phase it activates CDK4 and this complex has a vital role in the cell cycle, as it phosphorylates the retinoblastoma protein $(\mathrm{Rb})$, promoting cell replication, after E2F is released. The E2F stimulates the transcription of cyclin E, which binds to CDK2 in the S phase, stimulating the synthesis of DNA [28]. The transition from $\mathrm{G} 2$ to $\mathrm{M}$ is initiated by the transcription of cyclin A, which forms a complex with CDK2 and regulates the events of the mitotic prophase. The carcinogenic process involves the acquisition of mutations that culminate with the abnormal expression of proteins, many of them involved in cell cycle control [29].

The strongest connection of oncogenesis with the cyclins comes from the study of cyclin D1, one of the most important regulators of the cell cycle. The expression of cyclin D1 in the G1 phase of the cell cycle appears to be dependent on the activation of ERK 1 and 2.The ERK is a MAP kinase. The family of MAP kinases includes ERK 1, 2, JNK and p38. The MAP kinases are activated by various extracellular stimuli and they transfer extracellular signals from the cytoplasm to the nucleus. The MAP kinases constitute one of the signal transduction pathways that culminate in the activation of transcription factors. These transcription factors generated by different signaling pathways act coordinately in regulating the expression of genes that encode proteins that control, for example, the cell cycle. The sustained activation of this pathway has been associated with activation of cyclin D1 and cell cycle progression [21].

Overexpression of cyclin D1 has been correlated with a shorter G1 phase, reduced dependence on growth factors and abnormal cell proliferation. This abnormal cell growth may favor the occurrence of other genetic alterations required for tumorigenesis. This overexpression

\begin{tabular}{|c|c|c|}
\hline References & Markers & Main findings \\
\hline $\begin{array}{l}\text { Esposito et al. } \\
\text { (17) }\end{array}$ & Ki67 and PCNA & There was no correlation of Ki67 and PCNA with TNM staging, nor with the degree of malignancy. \\
\hline $\begin{array}{l}\text { Bettendorf, } \\
\text { Herrmann (16) }\end{array}$ & Ki67 & $\begin{array}{l}\text { No correlation could be established between the Ki- } 67 \text { immunostaining and histological and clinical parameters. Highly significant } \\
\text { inverse correlation was found between the } \mathrm{Ki}-67 \text {, the stroma/tumour proportion and the degree of keratinization. }\end{array}$ \\
\hline $\begin{array}{l}\text { Tumuluri et } \\
\text { al. (3) }\end{array}$ & Ki-67 & Well-differentiated tumors having the lowest mean Ki-67 immunostaining. \\
\hline $\begin{array}{l}\text { Kurokawa et } \\
\text { al. (14) }\end{array}$ & Ki-67 and p53 & Overexpression of $\mathrm{Ki}-67$ and p53 at the deep tumor invasive front of OSCC is associated with histologic grade of malignancy. \\
\hline $\begin{array}{l}\text { Myong et al. } \\
\text { (19) }\end{array}$ & PCNA and Ki67 & $\begin{array}{l}\text { Immunostaining increased in tumors with cervical lymph node metastasis. Ki-67 and clinical stage as independent prognostic factor } \\
\text { in evaluating survival in patients with OSCC. }\end{array}$ \\
\hline Kim et al. (18) & Ki67 & $\begin{array}{l}\text { The higher immunoexpression of Ki- } 67 \text { was associated with a worse survival rate, suggesting that may be useful in predicting the } \\
\text { prognosis of OSCC. }\end{array}$ \\
\hline $\begin{array}{l}\text { Watanabe et al. } \\
(22)\end{array}$ & $\begin{array}{l}\text { Ki-67, PCNA and } \\
\text { Cyclin B1 }\end{array}$ & $\begin{array}{l}\text { The expression of Ki- } 67 \text { and cyclin B1 were significantly stronger in OSCC than normal oral mucosa. The levels of Ki- } 67 \text { were higher } \\
\text { in floor of the mouth. Cyclin B1 showed a positive correlation with histological grade. PCNA was higher in the normal oral mucosa } \\
\text { than in the OSCC. }\end{array}$ \\
\hline $\begin{array}{l}\text { Angadi et al. } \\
\text { (26) }\end{array}$ & Cyclin D1 & Overexpression of cyclin D1 in OSCC. High immunostaining was associated with a histological grade of malignancy. \\
\hline $\begin{array}{l}\text { Thomson et al. } \\
\text { (29) }\end{array}$ & Cyclin A & $\begin{array}{l}\text { High immunostaining was associated with a worse clinical outcome suggests a role for cyclin A as a predictive tool in the clinical } \\
\text { behavior of the OSCC. }\end{array}$ \\
\hline Wang et al. (21) & $\begin{array}{l}\text { Cyclin D1, } \\
\text { ERK1/2 e Ki67 }\end{array}$ & $\begin{array}{l}\text { The expression of Ki67, ERK1/2 and cyclin D1 was significantly stronger in OSCC than in normal oral mucosa. Positive correlations } \\
\text { were observed between ERK1/2 and cyclin D1, and between ERK1/2 and Ki67, indicating that the MAP kinase pathway is involved } \\
\text { in the OSCC. }\end{array}$ \\
\hline $\begin{array}{l}\text { Mishra et al. } \\
(28)\end{array}$ & Cyclin D1 & $\begin{array}{l}\text { Percentage of immunopositivity and intensity of labeling for cyclin D1 was significantly higher in poorly differentiated compared to } \\
\text { well differentiated OSCC, suggesting an association between expression of cyclin D1 with the severity of dysplasia and carcinomas. }\end{array}$ \\
\hline
\end{tabular}

Table 1 Cell proliferative activity in oral squamous cell carcinoma. 
Citation: de Moraes M, Monteiro Maia CAD, de Almeida Freitas R, Galvão HC (2012) Cell proliferation markers in oral squamous cell carcinoma. J Mol Biomark Diagn S2:006. doi:10.4172/2155-9929.S2-006

Page 4 of 5

has been correlated with other proliferation markers (Ki67, PCNA) and associated with various tumors such as breast, liver, colon, esophagus and lung. This aberrant expression has also been associated with a poor survival, poor prognosis, with smoking cigarettes habit, the more advanced clinical stages and a higher risk of metastasis and recurrence in oral squamous cell carcinoma $[26,29]$.

\section{New cell proliferation markers}

Mcm and geminin: Minichromosome maintenance proteins (MCM) are proteins that regulate the cell cycle. MCM promotes the initiation of DNA synthesis and geminin helps regulate cellular differentiation and proliferation. Both have been used as effective markers for early detection of cancer, especially in samples with suspected malignant epithelial tumor [30].

MCM proteins (2 to 7) are required for DNA replication and initiation of the cell cycle [30]. Their ability to be expressed during all phases of the cell cycle gives these proteins the capacity to identify cells capable of proliferation. MCMs are expressed in abundance in all phases of the cell cycle but they are degraded in cells that have exited the cell cycle, such as quiescent, senescent or differentiated cells [28]. MCM-5 and MCM-2 have been proposed as potential prognostic markers in dysplastic lesions and cancer [1,11].

The geminin is present from the transition from G1 to the S phase until the onset of the $\mathrm{M}$ phase of the cell cycle. It regulates the initiation of the cell cycle by preventing a re-replication $[20,30]$. Therefore, the geminin labelling index identifies the number of actively proliferating cells that have progressed past G1 phase but have not exited mitosis [28]. The geminin overexpression has been correlated with poor prognosis in breast, kidney and colorectal cancers [20].

Tamura et al. [20] found correlation between MCM-7 and histological grade in OSCC, where increased immunostaining was observed in the poorly differentiated type. The survival rate was significantly lower in patients with a high labeling index for MCM-7 than in less. However, in OSCC the survival rate for patients with high immunostaining for geminin was significantly higher than in those with less immunostaining.

Szelachowska et al. [34] evaluated the immunoexpression of MCM2 protein and $\mathrm{Ki} 67$ in OSCC and compared their prognostic value suggesting that the expression of MCM-2 protein can be used not only to estimate the proliferative index, but also as a prognostic factor for the survival of patients with OSCC. A correlation between the expression of MCM-2 and Ki-67 was significant. No significant correlation could be detected between the proportion of cells with MCM-2 and Ki-67 expressions and the remaining clinicopathological factors studied.

Gueiros et al. [35] evaluated the clinicopathological features and immunohistochemical expression of proliferation markers in oral tongue squamous cell carcinomas (OTSCC). Elevated MCM2 immunoexpression was related to nodal recurrence and advanced disease stage, Ki-67 with distant metastasis and geminin was related to perineural invasion, failed to show any significant association with clinical features, favoring one possible poor prognosis.

The combined use of these two new biomarkers with the Ki-67 may provide important information about the rates of proliferation [36]. Torres-Rendon et al. [30] still believe that the MCM-2 is a proliferation marker superior to Ki67 due to its ability to identify cells that have not entered the cell cycle, but have the ability to divide. The relationship geminin/Ki-67 can potentially evaluate the relative length of the G1 phase. Another suggested prognostic parameter is the ratio MCM-2/ Ki-67 [37] which can estimate the proportion of cells able to proliferate (early G1).

\section{Conclusion}

The squamous cell carcinoma remains one of the major malignancies of the oral cavity. The study of cell proliferation is paramount for the assessment of tumor behavior, and the studies described above demonstrate that this parameter has been continually linked with the assessment of prognosis, patient survival and also with tumor staging. Proliferation markers provide important information when predicting the prognosis of patients with OSCC, so histopathological grading systems together with proliferation marker expression may be useful tools for evaluating the biological behavior of OSCC. Despite the advances in diagnosis and cancer therapy, understanding the functions of these biomarkers provides important tools in formulating an adequate treatment plan for oral squamous cell carcinoma.

\section{References}

1. Moura SAB, Catão MH, Gerbi M, Beltrão RV, Sales MAO, et al. (2006) Biologic markers in oral cancer. Int J Dent 1: 58-62

2. Van Diest PJ, Brugal G, Baak JP (1998) Proliferation markers in tumours: interpretation and clinical value. J Clin Pathol 51:716-724.

3. Tumuluri V, Thomas GA, Fraser IS (2002) Analysis of the Ki-67 antigen at the invasive tumour front of human oral squamous cell carcinoma. J Oral Patho Med 31:598-604

4. Todd R, Hinds PW, Munger K, Rustgi AK, Opitz OG, et al. (2002) Cell Cycle Dysregulation in Oral Cancer. Crit Rev Oral Biol Med 13: 51-61.

5. Scully C, Field JK, Tanzawa H (2000) Genetic aberrations in oral or head and neck squamous cell carcinoma (SCCHN): 1. Carcinogen metabolism, DNA repair and cell cycle control. Oral Oncology 36:256-263.

6. Baak JPA (1990) Mitosis counting in tumours. Hum Pathol 21:683-685.

7. Brinkmann BMN, Wong DTW (2006) Disease mechanism and biomarkers of oral squamous cell carcinoma. Curr Opin Oncol 18:228-233.

8. Pich A, Chiusa L, Navone R (2004) Prognostic relevance of cell proliferation in head and neck tumors. Annals of Oncology 15:1319-1329.

9. Derenzini M (2000) The AgNORs. Micron 31:117-120.

10. Trerè D (2000) AgNORs stainig and quantification. Micron 31:127-131.

11. Derenzini M, Pession A, Farabegoli F, Trerè D, Badiali M, et al. (1989) Relationship between interphasic nucleolar organizer regions and growth rate in two neurolastoma cell lines. Am J Pathol 134: 925-932.

12. Piffkò J, Bànkfalvi $A$, Ofner D, Bryne M, Rasch D, et al. (1997) Prognostic value of histobiological factors (malignancy grading and AgNOR content) assessed at the invasive tumour front of oral squamous cell carcinomas. $\mathrm{Br} \mathrm{J}$ Cance $75: 1543-6$.

13. López-Blanc SA Collet AM, Gandolfo MS, Femopase F, Hernández SL, et al. (2009) Nucleolar organizer regions (AgNOR) and subepithelial vascularization as field cancerization markers in oral mucosa biopsies of alcoholic and smoking patients. Oral Surg Oral Med Oral Pathol Oral Radiol Endod 108:747-753.

14. Brown DC, Gatter KC (2002) Ki67 protein: the immaculate deception? Histopathol 40: 2-11.

15. Kurokawa H, Zhang M, Matsumoto S, Yamachita Y, Tanaka T, et al. (2005) The relationship of the histologic grade at the deep invasive front and the expression of Ki-67 antigen and p53 protein in oral squamous cell carcinoma. Oral Pathol Med 34: 602-607.

16. Bettendorf O, Hermann G (2002) Prognostic relevance of $\mathrm{Ki}-67$ antigen expression in 329 cases of oral squamous cell carcinoma. ORL Otorhinolaryngol Relat Spec 64: 200-205.

17. Esposito JP, Camargo RS, Filho AL, Di Loreto C, Kanamura CT, et al. (2000) Expressão imuno-histoquímica dos marcadores PCNA, Ki-67e p53 em carcinomas epidermóides do trato aerodigestivo superior. Rev Col Bras Cir 27: $327-31$. 
Citation: de Moraes M, Monteiro Maia CAD, de Almeida Freitas R, Galvão HC (2012) Cell proliferation markers in oral squamous cell carcinoma. J Mol Biomark Diagn S2:006. doi:10.4172/2155-9929.S2-006

18. Kim SJ, Shin HJ, Jung K-Y, Baek S-K, Shin BK, et al. (2007) Prognostic Value of Carbonic Anhydrase IX and Ki-67 Expression in Squamous Cell Carcinoma of the Tongue. Jpn J Clin Oncol 37: 812-9.

19. Myoung H, Kim M-J, Lee J-H, Y-J, Paeng J-Y, Yun P-Y (2006) Correlation of proliferative markers [Ki-67 and PCNA] with survival and lymph node metastasis in oral squamous cell carcinoma: a clinical and histopathological analysis of 113 patients. Int J Oral Maxillofac Surg 35:1005-1110.

20. Tamura T, Shomori K, Haruki T, Nosaka K, Hamamoto $Y$, et al. (2010) Minichromosome maintenance- 7 and geminin are reliable prognostic markers in patients with oral squamous cell carcinoma: immunohistochemical study. $J$ Oral Pathol Med 39:328-334.

21. Wang L, Liu T, Nishioka M, Aguirre RL, Win SS, et al. (2006) Activation of ERK1/2 and cyclin D1 expression in oral tongue squamous cell carcinomas: relationship between clinic pathological appearances and cell proliferation. Oral Oncol 42: 625-631.

22. Watanabe S, Watanabe R, Oton-Leite AF, Alencar RCG, Oliveira JC, et al (2010) Analysis of cell proliferation and pattern of invasion in oral squamous carcinoma. J Oral Sci 52: 417-424.

23. Prives C, Gottifredi V (2008) The p21 and PCNA partnership. Cell Cycle 7 :3840-3846.

24. Naryzhny SN (2008) Proliferating cell nuclear antigen: a proteomics view. Cell Mol Life Sci 65: 3789-3808.

25. Moldovan GL, Pfander B, Jentsch S (2007) PCNA, the Maestro of the Replication Fork. Cell 129:665-679.

26. Angadi PV, Krishnapillai R (2007) Cyclin D1 expression in oral squamous cell carcinoma and verrucous carcinoma: correlation with histological differentiation. Oral Surg Oral Med Oral Pathol Oral Radiol Endod 103 : e30-5.

27. Chen HM, Kuo MYP, Lin KH, Lin C-Y, Chiang CP (2003) Expression of cyclin $A$ is related to progression of oral squamous cell carcinoma in Taiwan. Oral Oncol 39: 476-82.
28. Mishra R, Das BR (2009) Cyclin D1 expression and its possible regulation in chewing tobacco mediated oral squamous cell carcinoma progression. Arch Oral Biol 54: 917-923.

29. Thomson PJ, Goodson ML, Booth C, Cragg N, Hamadah O ( 2006) Cyclin A activity predicts clinical outcome in oral precancer and cancer. Int $\mathrm{J}$ Oral Maxillofac Surg 35: 1041-1046

30. Torres-Rendon A, Roy S, Craig GT, Speight PM (2009) Expression of MCM2, geminin and Ki-67 in normal oral mucosa, oral dysplasias and their corresponding squamous-cell carcinomas. Br J Cancer 100: 1128-1134.

31. Tachibana KE, Gonzales MA, Coleman N (2005) Cell-cycle-dependent regulation of DNA replication and its relevance to cancer pathology. J Patho 205: 123-129.

32. Alison MR, Hunt T, Forbes SJ (2002) Mini chromosome maintenance (MCM) proteins may be pre-cancer markers. Gut 50: 290-291.

33. Going JJ, Keith WN, Neilson L, Stoeber K, Stuart RC, et al. (2002) Aberran expression of minichromosome maintenance proteins 2 and 5 , and $\mathrm{Ki}-67$ in dysplastic squamous oesophageal epithelium and Barrett's mucosa. Gut 50 373-377.

34. Szelachowska J, Dziegiel P, JelenKrzeszewska J, Jelen M, Matkowski R, et al. (2006) MCM-2 protein expression predicts prognosis better than Ki7 antigen in oral cavity squamocellular carcinoma. Anticancer Research 26: 2473-2478.

35. Gueiros LA, Coletta RD, Kowalski LP, Lopes MA. (2011) Clinicopathologica features and proliferation markers in tongue squamous cell carcinomas. Int $J$ Oral Maxillofac Surg 40: 510-515

36. Quaglia A, McStay M, Stoeber K, Loddo M, Caplin M, et al. (2006) Nove markers of cell kinetics to evaluate progression from cirrhosis to hepatocellula carcinoma. Liver Int 26: 424-432.

37. Shetty A, Loddo M, Fanshawe T, Prevost AT, Sainsbury R, et al. (2005) DNA replication licensing and cell cycle kinetics of normal and neoplastic breast. $\mathrm{Br}$ J Cancer 93:1295-1300.
This article was originally published in a special issue, Cancer Biomarkers handled by Editor(s). Dr. Sudhir Srivastava, Cancer Biomarkers Research Group, National Institute of Health, USA; Dr. Shou-Jiang Gao, The University of Texas Health Science Centre at San Antonio, USA; Dr. Kenneth Maiese, University of Medicine \& Dentistry of New Jersey, New Jersey Medical School, USA 